\title{
Assessment of methods for estimation of effective atomic numbers of common human organ and tissue substitutes: waxes, plastics and polymers
}

\author{
V.P. Singh ${ }^{1 \mathrm{ab}}$, N.M. Badiger ${ }^{1}$ and N. Kucuk ${ }^{2}$ \\ 1 Department of Physics, Karnatak University, Dharwad, 580003, India. \\ 2 Department of Physics, Faculty of Arts and Sciences, Uludag University, 16059 Bursa, Turkey.
}

Received 18 April 2013 - Accepted 8 October 2013

\begin{abstract}
We calculated mass attenuation coefficients, effective atomic numbers and Kerma relative to air for human organ and tissue substitutes (i.e. wax, plastic and polymer materials). The effective atomic numbers of the tissue substitutes were calculated by the direct method, interpolation method, Auto- $Z_{\text {eff }}$ software and single value XMuDat program and then compared. The calculated effective atomic numbers were also compared with available experimental data and a good agreement was observed. A large difference in effective atomic numbers calculated by the direct and interpolation methods was observed in photoelectric and pair-production regions. The direct method was found to be appropriate for effective atomic number computation in low- $(>10 \mathrm{keV})$ and medium- $(0.1 \leq E \leq 10 \mathrm{MeV})$ photon energy regions. Kerma relative to air of the selected tissue substitutes was found to be dependent upon the atomic number and element compositions, which show a sharp peak due to K-edge absorption.
\end{abstract}

Keywords: wax / plastic / polymer / effective atomic number / Compton scattering / Kerma

\section{Introduction}

Simulation of radiation dose distribution in human organs and tissues is done by tissue-equivalent materials. The tissueequivalent materials are used as tissue substitutes for various organs of the human body, having similar properties with respect to ionizing radiation interactions. Tissue substitutes are made of low-atomic-number materials ( $\mathrm{H}, \mathrm{C}, \mathrm{N}, \mathrm{O}, \mathrm{F}, \mathrm{Cl}$, etc.). ICRU report 44 describes various types of tissue substitutes for human organs and tissues (ICRU, 1989) for diagnostic and therapeutic radiology, research, nuclear engineering, nuclear physics, health physics, radiation physics, medical physics, radiation dosimetry and radiation protection. Waxes, plastics and polymers are the choice for human organ and tissue substitutes due to their physical and chemical properties, ease of processing, significantly lower cost, low maintenance, and stability in the environment, which are used as a matrix of metals, and easy to shape. The waxes, plastics and polymers are used in phantom tissue substitutes for dosimetry services and calibration of radiation detectors.

Some photon interaction studies have been reported for low-Z materials in the low-energy photon region (Parthsaradhi et al., 1992; Tejbir et al., 2009, 2010; Murat and Yuksel, 2011). The effective atomic number of rubbers containing varying degrees of carbon contents has been investigated, showing a

\footnotetext{
${ }^{a}$ kudphyvps@rediffmail.com

b Permanent address: Health Physics Section, Kaiga Atomic Power Station-3\&4, NPCIL, Karwar, 581400, India.
}

range of effective atomic numbers (Elias et al., 1983). Mass attenuation coefficients of tissue-equivalent materials used for human tissue simulation have been investigated, comparing densities and attenuation coefficients (Ferreira et al., 2010). No detailed comparative study of photon interaction with the waxes, plastics and polymers used for tissue substitutes, shielding, dosimetry and medical physics is found in the literature at present. Keeping in mind the wide applications of the waxes, plastics and polymers, we investigated mass attenuation coefficients, $\mu_{\mathrm{m}}$, effective atomic numbers and Kerma relative to air, $K_{a}$, of the human organ and tissue substitutes given in Table 1.

Several authors have reported the effective atomic numbers for gaseous mixtures (Singh and Badiger, 2012), alcohols (Singh and Badiger, 2013), composite materials (Prasanna et al., 2010), solutions (Kulwant et al., 2001), dosimetric materials (Kiran and Venkata, 1997) and biological materials (Koç and Özyol, 2000; Shivalinge et al., 2005; Manjunathguru and Umesh, 2006; Demir et al., 2012). This study will be helpful for additional information and deciding the appropriate method for computation of the effective atomic numbers analogous to the experimental values.

\section{Computational work}

The mass attenuation coefficients and effective atomic numbers of the selected human organ and tissue substitutes 
Table 1. Elemental weight (\%) of waxes, plastics and polymers for tissue substitution.

\begin{tabular}{|c|c|c|c|c|c|c|c|c|}
\hline \multirow{2}{*}{ Serial Number } & \multirow{2}{*}{ Tissue Substitutes } & \multicolumn{7}{|c|}{ Element weight $(\%)$} \\
\hline & & $\mathbf{H}$ & $\mathbf{C}$ & $\mathbf{N}$ & $\mathbf{O}$ & $\mathbf{F}$ & $\mathbf{S}$ & $\mathbf{C l}$ \\
\hline 1 & Poly-Vinyl-Chloride (PVC) & 4.84 & 38.44 & - & - & - & - & 56.73 \\
\hline 2 & Synthetic Rubber (SR) & 5.69 & 54.26 & - & - & - & - & 40.04 \\
\hline 3 & Epoxy-Resin (ER) & 6.41 & 64.20 & - & 20.36 & - & - & 9.02 \\
\hline 4 & Poly-Chloro-Styrene (PCS) & 6.19 & 69.63 & - & - & - & - & 24.18 \\
\hline 5 & Poly-PhenyleneSulfide (PPS) & 3.73 & 66.63 & - & - & - & 29.65 & - \\
\hline 6 & Poly-Sulfone (PSU) & 5.01 & 73.28 & - & 14.46 & - & 7.25 & - \\
\hline 7 & Poly-Ether-Sulfone(PES) & 2.72 & 48.63 & - & 16.19 & - & 32.46 & - \\
\hline 8 & Modeling Clay (MC) & - & 19.76 & - & 75.83 & - & 3.55 & - \\
\hline 9 & Natural Rubber (NR) & 11.84 & 88.16 & - & - & - & - & - \\
\hline 10 & Poly-Propylene (PP) & 14.37 & 85.63 & - & - & - & - & - \\
\hline 11 & Plastic-Scintilattor (PSc) & 8.53 & 91.47 & - & - & - & - & - \\
\hline 12 & Bakelite (BK) & 5.74 & 77.46 & - & 16.80 & - & - & - \\
\hline 13 & Teflon (TF) & - & 24.02 & - & - & 75.98 & - & - \\
\hline 14 & Orange Articulation Wax (OAW) & 2.72 & 82.00 & 7.37 & 7.82 & - & 0.08 & - \\
\hline 15 & Bee Wax (BW) & 1.87 & 75.25 & 8.42 & 14.27 & - & 0.19 & - \\
\hline
\end{tabular}

are derived by computation of mass attenuation coefficients and atomic cross-sections of the elements of the waxes, plastics and polymers. We computed the effective atomic numbers of the human organ and tissue substitutes by the direct method, interpolation method, Auto- $Z_{\text {eff }}$ software and single value XMuDat program.

\subsection{Mass attenuation coefficients}

The $\mu_{m}(=\mu / \rho)$ values of human organ and tissue substitutes were calculated by the mixture rule, $(\mu / \rho)_{\text {composite }}=$ $\sum_{i}^{n} w_{i}(\mu / \rho)_{i}$ where $w_{i}$ is the proportion by weight and $(\mu / \rho)_{i}$ is the mass attenuation coefficient of the $i$ th element, using the XCOM program (Berger et al., 2010). Mass attenuation coefficients and attenuation cross-section data are available for 100 elements in the wide energy range from $1 \mathrm{keV}$ to $100 \mathrm{GeV}$, which has been transformed into the user-friendly software package WinXCom (Gerward et al., 2004) for the Windows platform. Using WinXCom software, mass attenuation coefficients and attenuation cross-section data are generated for the elements in the photon energy region from $1 \mathrm{keV}$ to $20 \mathrm{MeV}$. The atomic number and atomic mass of the elements were taken from atomic weight of elements 2011, IUPAC (Michael et al., 2013).

\subsection{Effective atomic numbers}

The effective atomic numbers of the composite material or compound can be calculated by the Auto- $Z_{\text {eff }}$ software, direct method, interpolation method and single value XMuDat program. These methods use the elemental compositions and molar composition of the element in the compound materials.

\subsubsection{Auto- $Z_{\text {eff }}$}

Auto- $Z_{\text {eff }}$ is user-friendly computer software in Visual Basic for rapid computation of the energy-dependent effective atomic number, average atomic numbers and spectralweighted mean atomic numbers. Auto- $Z_{\text {eff }}$ surpasses the dubious power-law approach. In this method, $Z_{\text {eff,Auto }}$ is determined via exploitation of the smooth correlation between the atomic cross-section and atomic number. A matrix of crosssections was constructed spanning atomic numbers $\mathrm{Z}=1-100$ for photon energies ranging between $10 \mathrm{keV}$ and $1 \mathrm{GeV}$, and cross-sections of poly-elemental media were calculated by linear additivity. The cross-section values are constructed with the cross-section matrix as a function of $\mathrm{Z}$, and an effective $\mathrm{Z}$ number for each energy is obtained by interpolation (b-spline) of $\mathrm{Z}$ values between adjacent cross-section data (Taylor et al., 2012).

\subsubsection{Direct method}

Computation of the effective atomic number, $\mathrm{Z}_{\mathrm{eff}}$ PI, of the waxes, plastics and polymers for total gamma photon interaction was carried out by the practical formula (Manohara et al., 2008). The mass attenuation coefficients of the elements were obtained from the WinXCom computer program. The effective atomic number, $\mathrm{Z}_{\mathrm{eff}, \mathrm{PI}}$, is given by

$$
\mathrm{Z}_{\mathrm{eff}, \mathrm{PI}}=\frac{\sum_{i} f_{i} \mathrm{~A}_{i}\left(\frac{\mu}{\rho}\right)_{i}}{\sum_{j} \frac{f_{i} \mathrm{~A}_{j}}{\mathrm{Z}_{j}}\left(\frac{\mu}{\rho}\right)_{j}}
$$

where $f_{i}$ is the molar fraction in the compound, $\mu$ is the linear attenuation coefficient, $\rho$ is the density, $\mu / \rho$ is the mass attenuation coefficient, $\mathrm{A}$ is the atomic weight, $\mathrm{Z}$ is the atomic number and the ratio, $\mathrm{A} / \mathrm{Z}$, between the atomic mass and the atomic number is approximately constant. 


\subsubsection{Interpolation method}

The $\mu_{\mathrm{m}}$ of the human organ and tissue substitutes are derived as mentioned above; the attenuation cross-section $(\sigma)$ values of human organ and tissue substitutes are computed by using the relation:

$$
\sigma=\frac{\left(\mu_{\mathrm{m}}\right)}{N \sum_{i}\left(\frac{w_{i}}{\mathrm{~A}_{i}}\right)}\left(\frac{\text { barns }}{\text { molecule }}\right)
$$

where $N=6.023 \times 10^{23}$ is Avogadro's number in atom. $\mathrm{g}^{-1}$, $w_{i}$ is the weight fraction of the $i$ th element in a molecule of the wax, plastic and polymer materials, and $\mathrm{A}_{i}$ is the atomic weight of the $i$ th element in a molecule. $w_{i}$ and $\mathrm{A}_{i}$ are both dimensionless quantities.

The attenuation cross-section values were interpolated in the attenuation cross-section values of the elements generated from WinXCom at selected energies to compute the effective atomic numbers using the logarithmic interpolation formula:

$$
\mathrm{Z}_{\mathrm{eq}}=\frac{\mathrm{Z}_{1}\left(\log \sigma_{2}-\log \sigma\right)+\mathrm{Z}_{2}\left(\log \sigma-\log \sigma_{1}\right)}{\log \sigma_{2}-\log \sigma_{1}}
$$

where $\sigma_{1}$ and $\sigma_{2}$ are the elemental cross-section (barn/atom) in between which the atomic cross-section $\sigma$ of the waxes, plastics and polymers lies, and $Z_{1}$ and $Z_{2}$ are the atomic numbers of the elements (dimensionless) corresponding to the crosssections $\sigma_{1}$ and $\sigma_{2}$, respectively.

\subsubsection{XMuDat}

The XMuDat computer program is able to produce a single-valued effective atomic number for compounds as well as mixtures (Nowotny, 1998). XMuDat uses the following formula for calculation of the effective atomic number:

$$
\mathrm{Z}_{\mathrm{eff}, X M u D a t}=\left(\sum_{i} \alpha_{i} \mathrm{Z}_{i}^{m-1}\right)^{\frac{1}{m-1}}
$$

where $\alpha_{i}$ is the fractional number of the electrons of the $i$ th element, and $m$ is a constant between 3 and 5 . It is preferred that $m$ is set to 3.6 for materials with $\mathrm{Z}_{\mathrm{eff}}<6$, and 4.1 for materials with $\mathrm{Z}_{\mathrm{eff}}>6$ (Jackson and Hawkers, 1981).

\subsection{Kerma}

Kerma relative to air of the human organ and tissue substitutes is derived by

$$
K_{a}=\frac{K_{\text {tissue substitutes }}}{K_{\text {Air }}}=\frac{\left(\frac{\mu_{\mathrm{en}}}{\rho}\right)_{\text {tissue substitutes }}}{\left(\frac{\mu_{\mathrm{en}}}{\rho}\right)_{\text {Air }}}
$$

Where $\left(\mu_{\mathrm{en}} / \rho\right)_{i}$ of tissue substitutes and air is calculated from the compilation of Hubbell (1982).

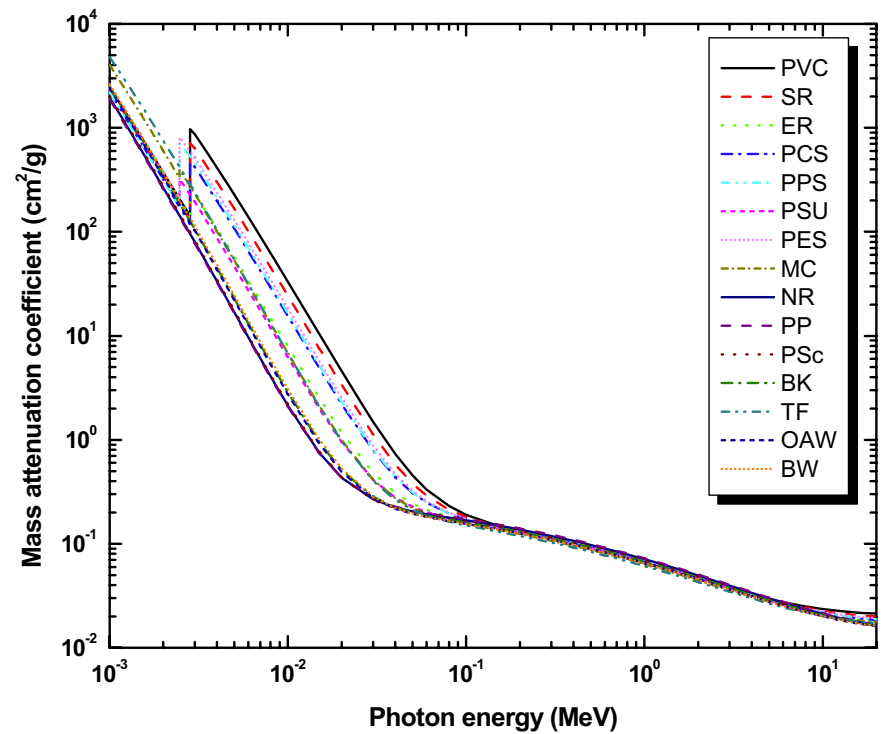

Fig. 1. Variation of mass attenuation coefficients with photon energy for waxes, plastics and polymers.

\section{Results and discussion}

The $\mu_{\mathrm{m}}$ values of the waxes, plastics and polymers for the photon energies $10^{-3}$ to $20 \mathrm{MeV}$ are shown in Figure 1 and explained by partial photon interactions (i.e. photoelectric absorption, Compton scattering and pair production). The effective atomic numbers computed by various methods in the photon energy region 0.01 to $20 \mathrm{MeV}$ are given in Table 2. The calculated effective atomic numbers at different energies were compared with the experimental values and are shown graphically in Figure 2. The $K_{a}$ is shown in Figure 3 and explained for photon energy, elemental atomic numbers and their composition dependencies.

\subsection{Mass attenuation coefficient}

The variation of the mass attenuation coefficient, $\mu_{\mathrm{m}}$, values of the tissue substitute materials with photon energy is shown in Figure 1 . The $\mu_{\mathrm{m}}$ values were found to be higher in low- as well as high-energy regions due to partial photon interaction processes, photoelectric absorption, Compton scattering and pair production in nuclear and electronic fields. It was observed that $\mu_{\mathrm{m}}$ values were maximum at $1 \mathrm{keV}$, which decreased very fast with an increase in photon energy up to $50 \mathrm{keV}$ for all the human organ and tissue substitutes except which contains ${ }_{17} \mathrm{Cl}$ and ${ }_{16} \mathrm{~S}$ elements such as PVC, SR, ER, PCS, PPS, PSU, PES and MC. These elements have a sudden jump in $\mu_{\mathrm{m}}$ values at $3 \mathrm{keV}$ due to K-edge absorption. We found that a small amount of ${ }_{32} \mathrm{~S}$ elements in the human organ and tissue substitutes did not appreciably alter $\mu_{\mathrm{m}}$ values (in the case of $\mathrm{BW}$ ). As photon energy increases, the $\mu_{\mathrm{m}}$ values slowly decrease for all the human organ and tissue substitutes up to $10 \mathrm{MeV}$ and then they gradually increase beyond $12 \mathrm{MeV}$ photon energy. The $\mu_{\mathrm{m}}$ values of PVC were found to be highest among all the selected human organ and tissue substitutes due to the maximum percentage composition of ${ }_{17} \mathrm{Cl}$ 
Table 2. Effective atomic numbers of tissue substitutes calculated by the Auto- $Z_{\text {eff }}$, direct and interpolation methods.

\begin{tabular}{|c|c|c|c|c|c|c|}
\hline \multirow{2}{*}{ Tissue substitutes } & \multirow{2}{*}{ Method } & \multicolumn{5}{|c|}{ Energy $(\mathrm{MeV})$} \\
\hline & & 0.01 & 0.1 & 1 & 10 & 20 \\
\hline \multirow{3}{*}{ PVC } & $\mathrm{Z}_{\text {eff,Auto }}$ & 10.91 & 6.45 & 5.34 & 6.21 & 6.74 \\
\hline & $Z_{\text {eff,PI }}$ & 16.05 & 6.13 & 5.34 & 6.4 & 7.4 \\
\hline & $\mathrm{Z}_{\mathrm{eq}}$ & 10.93 & 6.48 & 5.37 & 6.23 & 6.77 \\
\hline \multirow{3}{*}{ SR } & $\mathrm{Z}_{\text {eff,Auto }}$ & 9.69 & 5.31 & 4.61 & 5.25 & 5.68 \\
\hline & $\mathrm{Z}_{\mathrm{eff,PI}}$ & 15.29 & 5.13 & 4.6 & 5.37 & 6.12 \\
\hline & $\mathrm{Z}_{\mathrm{eq}}$ & 9.73 & 5.34 & 4.63 & 5.27 & 5.7 \\
\hline \multirow{3}{*}{ ER } & $\mathrm{Z}_{\text {eff,Auto }}$ & 7.14 & 4.19 & 4.18 & 4.32 & 4.55 \\
\hline & $\mathrm{Z}_{\mathrm{eff}, \mathrm{PI}}$ & 10.8 & 4.14 & 4 & 4.37 & 4.76 \\
\hline & $\mathrm{Z}_{\mathrm{eq}}$ & 7.15 & 4.21 & 4 & 4.35 & 4.59 \\
\hline \multirow{3}{*}{ PCS } & $\mathrm{Z}_{\mathrm{eff}, \text { Auto }}$ & 8.46 & 4.57 & 4.17 & 4.61 & 4.94 \\
\hline & $\mathrm{Z}_{\mathrm{eff}, \mathrm{PI}}$ & 13.94 & 4.47 & 4.16 & 4.69 & 5.23 \\
\hline & $\mathrm{Z}_{\mathrm{eq}}$ & 8.52 & 4.6 & 4.18 & 4.64 & 4.95 \\
\hline \multirow{3}{*}{ PPS } & $\mathrm{Z}_{\text {eff,Auto }}$ & 9.07 & 5.59 & 5.09 & 5.57 & 5.89 \\
\hline & $\mathrm{Z}_{\mathrm{eff}, \mathrm{PI}}$ & 13.64 & 5.45 & 5.1 & 5.67 & 6.22 \\
\hline & $\mathrm{Z}_{\mathrm{eq}}$ & 9.08 & 5.61 & 5.1 & 5.6 & 5.9 \\
\hline \multirow{3}{*}{ PSU } & $\mathrm{Z}_{\text {eff,Auto }}$ & 6.88 & 4.45 & 4.3 & 4.57 & 4.77 \\
\hline & $\mathrm{Z}_{\mathrm{eff}, \mathrm{PI}}$ & 9.71 & 4.4 & 4.3 & 4.62 & 4.95 \\
\hline & $\mathrm{Z}_{\mathrm{eq}}$ & 6.91 & 4.47 & 4.32 & 4.6 & 4.8 \\
\hline \multirow{3}{*}{ PES } & $\mathrm{Z}_{\text {eff,Auto }}$ & 9.63 & 6.45 & 5.85 & 6.37 & 6.69 \\
\hline & $\mathrm{Z}_{\mathrm{eff,PI}}$ & 13.73 & 6.26 & 5.85 & 6.49 & 7.07 \\
\hline & $\mathrm{Z}_{\mathrm{eq}}$ & 9.68 & 6.47 & 5.87 & 6.39 & 6.71 \\
\hline \multirow{3}{*}{$\mathrm{MC}$} & $Z_{\text {eff,Auto }}$ & 8.14 & 7.7 & 7.63 & 7.67 & 7.69 \\
\hline & $\mathrm{Z}_{\mathrm{eff}, \mathrm{PI}}$ & 8.96 & 7.68 & 7.62 & 7.68 & 7.73 \\
\hline & $\mathrm{Z}_{\mathrm{eq}}$ & 8.17 & 7.71 & 7.64 & 7.68 & 7.71 \\
\hline \multirow{3}{*}{ NR } & $Z_{\text {eff,Auto }}$ & 4.69 & 2.96 & 2.92 & 3.11 & 3.27 \\
\hline & $\mathrm{Z}_{\mathrm{eff}, \mathrm{PI}}$ & 5.42 & 2.95 & 2.92 & 3.14 & 3.38 \\
\hline & $\mathrm{Z}_{\mathrm{eq}}$ & 4.77 & 2.97 & 2.94 & 3.13 & 3.31 \\
\hline \multirow{3}{*}{ PP } & $\mathrm{Z}_{\text {eff,Auto }}$ & 4.21 & 2.27 & 2.25 & 2.4 & 2.55 \\
\hline & $\mathrm{Z}_{\mathrm{eff}, \mathrm{PI}}$ & 5.3 & 2.69 & 2.67 & 2.87 & 3.1 \\
\hline & $\mathrm{Z}_{\mathrm{eq}}$ & 4.61 & 2.73 & 2.71 & 2.87 & 3.02 \\
\hline \multirow{3}{*}{ PSc } & $\mathrm{Z}_{\text {eff,Auto }}$ & 5.01 & 3.41 & 3.37 & 3.56 & 3.72 \\
\hline & $\mathrm{Z}_{\mathrm{eff}, \mathrm{PI}}$ & 5.58 & 3.39 & 3.37 & 3.59 & 3.83 \\
\hline & $\mathrm{Z}_{\mathrm{eq}}$ & 5.01 & 3.44 & 3.4 & 3.6 & 3.75 \\
\hline \multirow{3}{*}{$\mathrm{BK}$} & $\mathrm{Z}_{\text {eff,Auto }}$ & 5.54 & 4.06 & 4 & 4.21 & 4.37 \\
\hline & $\mathrm{Z}_{\mathrm{eff}, \mathrm{PI}}$ & 6.31 & 4.03 & 4 & 4.25 & 4.51 \\
\hline & $\mathrm{Z}_{\mathrm{eq}}$ & 5.63 & 4.06 & 4 & 4.23 & 4.4 \\
\hline \multirow{3}{*}{$\mathrm{TF}$} & $\mathrm{Z}_{\text {eff,Auto }}$ & 8.3 & 8.05 & 8 & 8.05 & 8.07 \\
\hline & $\mathrm{Z}_{\mathrm{eff}, \mathrm{PI}}$ & 8.64 & 8.03 & 8 & 8.06 & 8.11 \\
\hline & $Z_{\mathrm{eq}}$ & 8.36 & 8.06 & 8.01 & 8.06 & 8.08 \\
\hline \multirow{3}{*}{ OAW } & $\mathrm{Z}_{\mathrm{eff}, \text { Auto }}$ & 5.84 & 4.91 & 4.86 & 5.02 & 5.13 \\
\hline & $\mathrm{Z}_{\mathrm{eff}, \mathrm{PI}}$ & 6.3 & 4.89 & 4.87 & 5.05 & 5.23 \\
\hline & $\mathrm{Z}_{\mathrm{eq}}$ & 5.88 & 4.92 & 4.88 & 5.02 & 5.14 \\
\hline \multirow{3}{*}{ BW } & $Z_{\text {eff,Auto }}$ & 6.13 & 5.34 & 5.29 & 5.42 & 5.51 \\
\hline & $\mathrm{Z}_{\mathrm{eff}, \mathrm{PI}}$ & 6.61 & 5.32 & 5.29 & 5.45 & 5.6 \\
\hline & $\mathrm{Z}_{\mathrm{eq}}$ & 6.17 & 5.36 & 5.31 & 5.45 & 5.54 \\
\hline
\end{tabular}



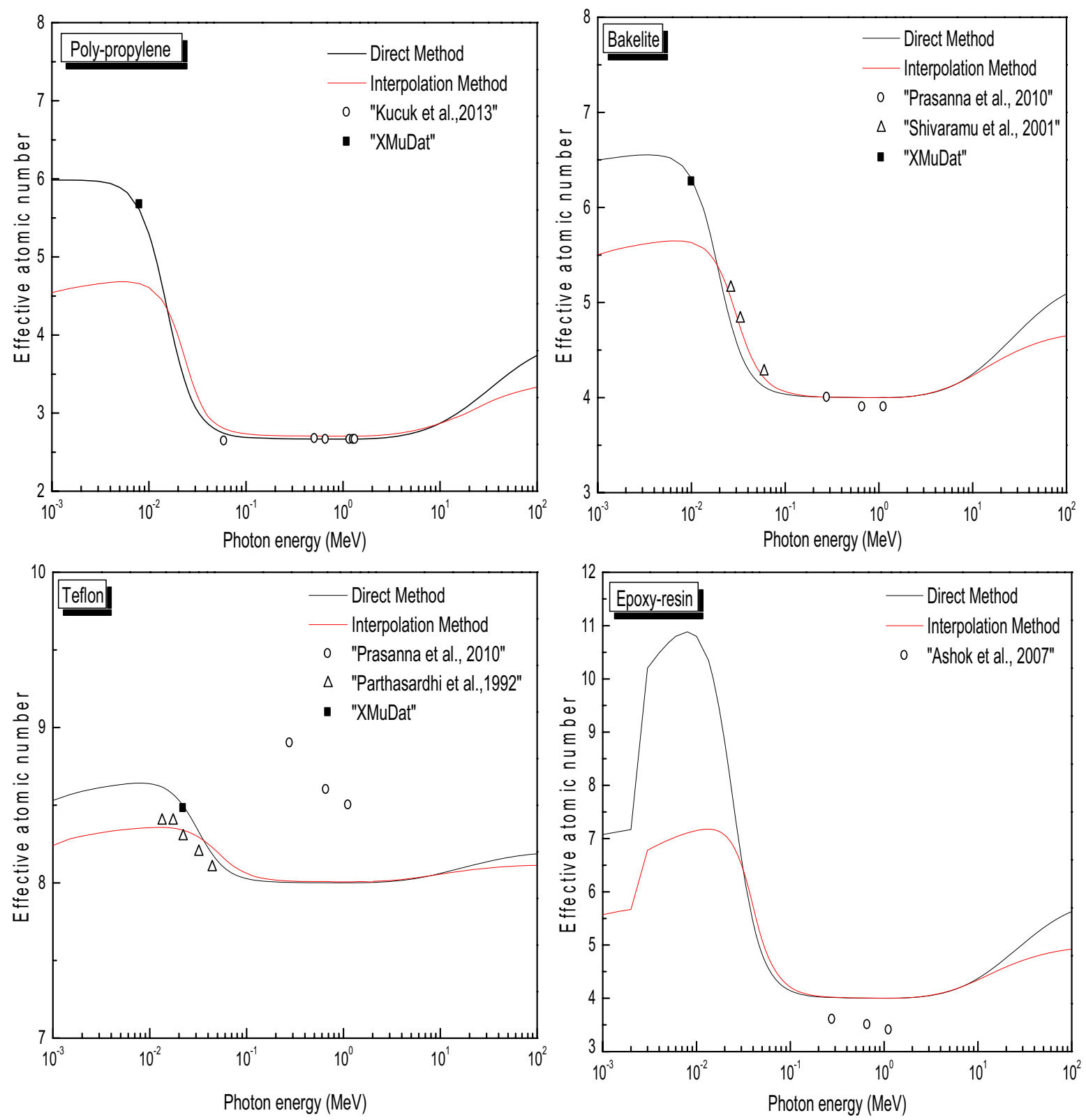

Fig. 2. Comparison of the calculated effective atomic numbers with the experimental values for waxes, plastics and polymers.

elements. It is to be noted that the $\mu_{\mathrm{m}}$ values of TF, ER, PES and BW are higher than PVC below $3 \mathrm{keV}$.

The tissue substitutes (i.e. waxes, plastics and polymers) had elemental atomic numbers ranging from $1<\mathrm{Z}<17$ (H: 1 , C: $6, \mathrm{~N}: 7, \mathrm{O}: 8, \mathrm{~S}: 16$ and $\mathrm{Cl}: 17)$. The sharp decrease in $\mu_{\mathrm{m}}$ values below $50 \mathrm{keV}$ is due to the dominance of the photo absorption, where the photon interaction cross-section depends on $\mathrm{Z}^{4-5}$ and photon energy as $\mathrm{E}^{-7 / 2}$. It is observed that the $\mu_{\mathrm{m}}$ values were in the range of $10^{3}$ to $10^{4} \mathrm{~cm}^{2} / \mathrm{g}$ (highest value) at photon energy 1-2 $\mathrm{keV}$. As photon energy increases, the atomic number of the element plays a vital role: therefore, the $\mu_{\mathrm{m}}$ values of PVC and SR were found to be the highest as they contain ${ }_{17} \mathrm{Cl}$ contents of $56.73 \%$ and $40 \%$, respectively. Beyond $50 \mathrm{keV}$, the Compton scattering process replaces photo absorption, where the photon interaction cross-section varies linearly with $\mathrm{Z}$ and $\mathrm{E}^{-1}$; thus, the $\mu_{\mathrm{m}}$ values become almost independent of photon energy and decrease slowly up to $10 \mathrm{MeV}$. With a further increase in photon energy, the pair-production process dominates, where the interaction cross-section depends on $\mathrm{Z}^{2}$ and $\log \mathrm{E}$, and hence the $\mu_{\mathrm{m}}$ values begin to increase slowly.

\subsection{Effective atomic numbers}

The effective atomic numbers calculated by the different methods in the photon energy region $10 \mathrm{keV}$ to $20 \mathrm{MeV}$ for the human organ and tissue substitutes are given in Table 2. The effective atomic numbers below $10 \mathrm{keV}$ were not compared due to high uncertainty $\pm 25 \%$ by Auto- $Z_{\text {eff }}$ (Taylor et al., 2012). 
It was found that the effective atomic numbers computed by the Auto- $\mathrm{Z}_{\mathrm{eff}}$, direct and interpolation methods were in good agreement in the energy region of $50 \mathrm{keV}$ to $10 \mathrm{MeV}$ where the Compton interaction process dominates. The effective atomic numbers were found to be constant in the medium-energy photon region, whereas significant variation was observed in the lower-energy photon region $(10-50 \mathrm{keV})$ as well as in the higher-energy photon region (10-20 MeV). The effective atomic numbers computed by the direct method are higher in the photo-absorption and pair-production regions compared with the interpolation method.

The variation in effective atomic numbers calculated by the Auto- $Z_{\text {eff }}$ software, direct and interpolation methods for the human organ and tissue substitutes may be due to the basic concept and input parameters. In the Auto- $Z_{\mathrm{eff}}$ software, the effective atomic number is determined via exploitation of the smooth correlation between the atomic cross-section, atomic number and mass attenuation coefficients. The cross-sections of poly-elemental compounds are calculated by linear additivity. The effective atomic numbers of the human organ and tissue substitutes are calculated by interpolation (b-spline) of Z values of adjacent cross-section data of the cross-section matrix as a function of $\mathrm{Z}$. The uncertainty in the effective atomic number by the Auto- $Z_{\text {eff }}$ method is of the order of $1-2 \%$ at high photon energy.

\subsection{Comparison with experiments}

Comparison of the effective atomic numbers calculated using the direct and interpolation methods in the present work with the experimental values is shown in Figure 2. The experimental values of the effective atomic numbers of PP, BK and ER (Parthsaradhi et al., 1992; Shivaramu et al., 2001; Ashok et al., 2007; Prasanna et al., 2010; Kucuk et al., 2013) in the Compton scattering-dominated region shows that the computed values in the present work are comparable. It is to be noted from the graphs that the effective atomic numbers in Compton region calculated by the direct and interpolation methods are in very good agreement. In the case of TF, the effective atomic number values are slightly distant from the calculation (Parthsaradhi et al., 1992; Prasanna et al., 2010). The reasons for this difference may be due to incoherent scattering cross-sections used for derivation of effective atomic numbers at the mentioned photon energies.

This comparative analysis shows that the effective atomic numbers derived by the direct method are appropriate in the photo-absorption region $(E>10 \mathrm{keV})$ and Comptondominated region. Below $10 \mathrm{keV}$ energy, experimental investigations are still required to find out the most suitable computational method for the effective atomic numbers. Our investigations into computation of effective atomic numbers signify that both the methods (direct and interpolation) used in our study are appropriate for Compton scattering for materials containing atomic numbers $1<\mathrm{Z}<17$.

\subsection{Kerma}

The kerma relative to air, $K_{a}$ variation of the tissue substitutes for photon energy ( $1 \mathrm{keV}-20 \mathrm{MeV})$ is shown in Figure $3 . K_{a}$ variation with photon energy represents variation of

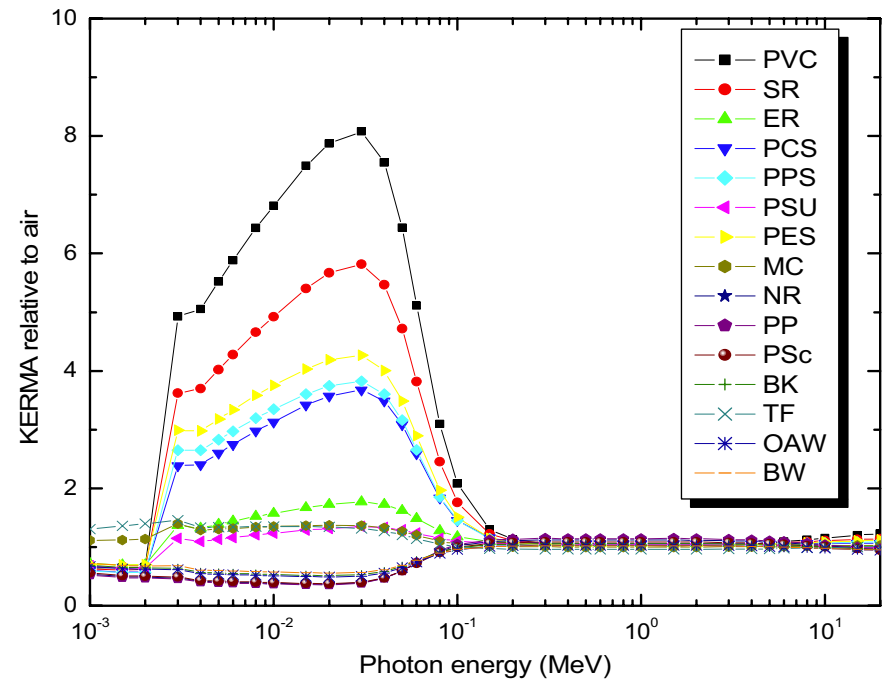

Fig. 3. Kerma relative to air as a function of photon energy for waxes, plastics and polymers.

the effective atomic numbers due to photo absorption, Compton scattering and pair production. It is to be noted that the $K_{a}$ values of PVC, containing the highest- $\mathrm{Z}$ materials $\left({ }_{17} \mathrm{Cl}\right)$, reaches up to 8.08 at $3 \mathrm{keV}$ compared with the others. Similarly SR, ER and PCS, containing ${ }_{17} \mathrm{Cl}$, and PPS, PSU, PES, $\mathrm{BW}$, OAW and MC, containing ${ }_{16} \mathrm{~S}$, show comparatively high $K_{a}$ values. The peak value of $K_{a}$ is due to the photoelectric effect around the K-absorption edge of ${ }_{17} \mathrm{Cl}(2.82 \mathrm{keV})$ and ${ }_{16} \mathrm{~S}$ $(2.47 \mathrm{keV})$ elements.

Figure 3 shows that the $K_{a}$ value for PVC rises sharply from 0.57 to 4.93 and after this it builds up to 8.07 and then decreases slowly. The reason behind this may be that the K-edge absorption produces X-rays which are absorbed by valance electrons to eject from atomic bonding. These electrons with kinetic energy increase $K_{a}$ values. As incident photon energy increases, the probability of K-edge absorption decreases; therefore, $K_{a}$ values reach maximum values and then slowly decrease.

Below $100 \mathrm{keV}$ photon energy, $K_{a}$ values are found to be less than unity for those human organ and tissue substitutes which have a negligible or zero fraction of high- $Z$ elements. We found that the $K_{a}$ values of all the waxes, plastics and polymers are constant ( $\sim$ unity) above photon energy $\sim 100 \mathrm{keV}$. It is also to be noted that $K_{a}$ values are found to be $<1$ below $100 \mathrm{keV}$ and $>1$ (1-1.1) above $100 \mathrm{keV}$ for materials without K-edge absorption elements.

\section{Conclusions}

In the present study, we computed and compared the effective atomic numbers of the human organ and tissue substitutes by various methods (i.e. the direct method, interpolation method, Auto- $Z_{\text {eff }}$ software and XMuDat program). The Auto- $Z_{\text {eff }}$, direct and interpolation methods are applicable at low photon energy (10 keV to $100 \mathrm{keV}$ ), where photo absorption dominates, and at medium photon energy (100 keV to $20 \mathrm{MeV}$ ), where Compton interaction dominates. A large 
difference in effective atomic numbers by the direct and interpolation methods is observed in photoelectric and pairproduction regions. The effective atomic numbers computed in the present work are in good agreement with the experiments. We also computed Kerma relative to air and found approximately unity except for chlorine-containing materials. Peaks in Kerma relative to air values are observed due to K-edge absorption of high- $\mathrm{Z}$ materials $\left({ }_{17} \mathrm{Cl}\right.$ and $\left.{ }_{32} \mathrm{~S}\right)$ in the photoabsorption region.

\section{References}

Ashok K., Sukhpal S., Gurmel S.M., Kulwant S.T. (2007) Studies on Effective Atomic Numbers and Electron Densities in Some Commonly Used Solvents, Nucl. Sci. Eng. 155, 102-108.

Berger M.J., Hubbell J.H., Seltzer S.M., Chang J., Coursey J.S., Sukumar R., Zucker D.S., Olsen K. (2010) XCOM: photon cross sections database, NIST standard reference database (XGAM), http://www.nist.gov/pml/data/xcom/index.cfm.

Demir D., Tursucu A., Oznuluer T. (2012) Studies on mass attenuation coefficient, effective atomic number and electron densitiy of some vitamins, Radiat. Environ. Biophys. DOI: $10.1007 / \mathrm{s} 00411-012-0427-8$.

Elias S., Zainal A.S., Anuar A., Husin W. (1983) Determination of effective atomic number of rubber, Pertanika 6, 95-98.

Ferreira C.C., Ximenes R.E., Garcia C.A.B., Viera J.W., Maia A.F. (2010) Total mass attenuation coefficient evaluation of ten materials commonly used to simulate human tissue, J. Phys.: Conf. Ser. 249, 1-5.

Gerward L., Guilbert N., Jensen K.B., Levring H. (2004) WinXCom a program for calculating X-ray attenuation coefficients, Radiat. Phys. Chem. 71, 653-654.

Hubbell J.H. (1982) Photon mass attenuation and energy-absorption coefficients from $1 \mathrm{keV}$ to $20 \mathrm{MeV}$, Int. J. Appl. Radiat. Isot. 33, 1269-1290.

ICRU (1989) International Commission on Radiation Units and Measurements. Tissue substitutes in radiation dosimetry and measurement, Report No. 44, Bethesda, MD.

Jackson D.F., Hawkers D.J. (1981) X-ray attenuation coefficient of the elements and mixtures, Phys. Rep. 70, 169-233.

Kiran T.K., Venkata K.R. (1997) Effective atomic numbers for materials of dosimetric interest, Radiat. Phys. Chem. 50 (6), 545-553.

Koç N., Özyol H. (2000) Z-dependence of partial and total photon interactions in some biological samples, Radiat. Phys. Chem. 59, 339-345.

Kucuk N., Cakir M., Isitman N.A. (2013) Mass attenuation coefficients, effective atomic numbers and effective electron densities for some polymers, Radiat. Prot. Dosim. 153 (1), 127-134.
Kulwant S., Gagandeep K., Sandhu G.K., Lark B.S. (2001) Interaction of photons with some solutions, Radiat. Phys. Chem. 61, 537-540.

Manjunathguru V., Umesh T.K. (2006) Effective atomic number and electron densities of some biologically important compounds containing $\mathrm{H}, \mathrm{C}, \mathrm{N}$ and $\mathrm{O}$ in energy range $145-1330 \mathrm{keV}$, J. Phys. B 39, 3969-3981.

Manohara S.R., Hanagodimath S.M., Thind K.S., Gerward L. (2008) On the effective atomic number and electron density: A comprehensive set of formulas for all types of materials and energies above 1 keV, Nucl. Instrum. Meth. Phys. Res. B 266, 3906-3912.

Michael E.W. et al. (2013) Atomic weight of elements 2011 (IUPAC Technical Report), Pure Appl. Chem. 85 (05), 1047-1078.

Murat K., Yuksel O. (2011) Energy absorption and exposure buildup factors for some polymer and tissue substitute materials: photon energy, penetration depth and chemical composition dependency, J. Radiol. Prot. 31, 117-128.

Nowotny R. (1998) XMuDat: Photon attenuation data on PC. IAEANDS-195, Vienna, Austria. Available on http://www-nds.iaea. org/publications/iaea-nds/iaea-nds-0195.htm.

Parthsaradhi K., Esposito A., Pelliccioni M. (1992) Photon attenuation coefficients in tissue equivalent compound, Appl. Radiat. Isotopes 43 (12), 1481-1484.

Prasanna K.S., Manjunathguru V., Umesh T.K. (2010) Effective atomic numbers of some $\mathrm{H}-, \mathrm{C}-$, O- based composite materials derived from differential incoherent scattering cross section, Pramana 74 (4), 555-562.

Shivalinge G., Krishnaveni S., Ramakrishna G. (2005) Studies on effective atomic numbers and electron densities in amino acids and sugars in the energy range 30-1333 keV, Nucl. Instr. Meth. Phys. Res. B 239 (4), 361-369.

Shivaramu R., Vijayakumar L., Rajasekaran N.R. (2001) Effective atomic numbers for photon energy absorption of some low-Z substances of dosimetric interest, Radiat. Phys. Chem. 62, 371-377.

Singh V.P., Badiger N.M. (2012) Effective atomic numbers, electron densities and tissue equivalence of some gases and mixtures for dosimetry of radiation detectors, Nuclear Technology $\mathcal{E}$ Radiation Protection 27 (2), 117-124.

Singh V.P., Badiger N.M. (2013) Study of effective atomic numbers and electron densities, kerma of alcohols: phantom and human organ tissue substitues, Nuclear Technology $\mathcal{E}$ Radiation Protection, 28 (2), 137-145

Taylor M.L., Smith R.L., Dossing F., Franich R.D. (2012) Robust calculation of effective atomic numbers: The Auto-Zeff software, Med. Phys. 39, 1769-1778.

Tejbir S., Naresh K., Parjit S.S. (2009) Chemical composition dependency of exposure buildup factors for some polymers, Ann. Nucl. Eng. 36, 114-120.

Tejbir S., Rajni Updesh K., Parjit S.S. (2010) Photon energy absorption parameters for some polymers, Ann. Nucl. Eng. 37, 422-427.

Cite this article as: V.P. Singh, N.M. Badiger, N. Kucuk. Assessment of methods for estimation of effective atomic numbers of common human organ and tissue substitutes: waxes, plastics and polymers. Radioprotection 49(2), 115-121 (2014). 